\title{
Iterative Algorithm and $\Delta$-Convergence Theorems for Total Asymptotically Nonexpansive Mappings in CAT(0) Spaces
}

\author{
J. F. Tang, ${ }^{1}$ S. S. Chang, ${ }^{2}$ H. W. Joseph Lee, ${ }^{3}$ and C. K. Chan ${ }^{3}$ \\ ${ }^{1}$ Department of Mathematics, Yibin University, Yibin, Sichuan 644007, China \\ ${ }^{2}$ College of Statistics and Mathematics, Yunnan University of Finance and Economics, Kunming, \\ Yunnan 650221, China \\ ${ }^{3}$ Department of Applied Mathematics, The Hong Kong Polytechnic University, Hong Kong
}

Correspondence should be addressed to S. S. Chang, changss@yahoo.cn

Received 9 July 2012; Accepted 9 August 2012

Academic Editor: Yongfu Su

Copyright (C) 2012 J. F. Tang et al. This is an open access article distributed under the Creative Commons Attribution License, which permits unrestricted use, distribution, and reproduction in any medium, provided the original work is properly cited.

The main purpose of this paper is first to introduce the concept of total asymptotically nonexpansive mappings and to prove a $\Delta$-convergence theorem for finding a common fixed point of the total asymptotically nonexpansive mappings and the asymptotically nonexpansive mappings. The demiclosed principle for this kind of mappings in CAT(0) space is also proved in the paper. Our results extend and improve many results in the literature.

\section{Introduction}

A metric space $X$ is a CAT(0) space if it is geodesically connected and if every geodesic triangle in $X$ is at least as "thin" as its comparison triangle in the Euclidean plane. Fixed point theory in a CAT(0) space was first studied by Kirk $[1,2]$. He showed that every nonexpansive mapping defined on a bounded closed convex subset of a complete CAT( 0$)$ space always has a fixed point. Since then the fixed point theory for various mappings in CAT(0) space has been developed rapidly and many papers have appeared [3-10]. On the other hand, Browder [11] introduced the demiclosed principle which states that if $X$ is a uniformly convex Banach space, $C$ is a nonempty closed convex subset of $X$, and if $T: C \rightarrow C$ is nonexpansive mapping, then $I-T$ is demiclosed at each $y \in X$, that is, for any sequence $\left\{x_{n}\right\}$ in $C$ conditions $x_{n} \rightarrow x$ weakly and $(I-T) x_{n} \rightarrow y$ strongly imply that $(I-T) x=y$ (where $I$ is the identity mapping of $X) . \mathrm{Xu}$ [12] proved the demiclosed principle for asymptotically nonexpansive mappings in the setting of a uniformly convex Banach space. Nanjaras and Panyanak [13] 
proved the demiclosed principle for asymptotically nonexpansive mappings in CAT $(0)$ space and obtained a $\Delta$-convergence theorem for the Krasnosel'skii-Mann iteration.

Motivated and inspired by the researches going on in this direction, especially inspired by Nanjaras and Panyanak, and so forth [13], the purpose of this paper is to introduce a general mapping, namely, total asymptotically nonexpansive mapping and to prove its demiclosed principle in CAT(0) space. As a consequence, we construct a hierarchical iterative algorithm to study the fixed point of the total asymptotically nonexpansive mappings and obtain a $\Delta$-convergence theorem.

\section{Preliminaries and Lemmas}

Let $(X, d)$ be a metric space and $x, y \in X$ with $d(x, y)=l$. A geodesic path from $x$ to $y$ is a isometry $c:[0, l] \rightarrow X$ such that $c(0)=x, c(l)=y$. The image of a geodesic path is called geodesic segment. A space $(X, d)$ is a (uniquely) geodesic space if every two points of $X$ are joined by only one geodesic segment. A geodesic triangle $\Delta\left(x_{1}, x_{2}, x_{3}\right)$ in a geodesic metric space $(X, d)$ consists of three points $x_{1}, x_{2}, x_{3}$ in $X$ (the vertices of $\Delta$ ) and a geodesic segment between each pair of vertices (the edges of $\Delta$ ). A comparison triangle for the geodesic triangle $\Delta\left(x_{1}, x_{2}, x_{3}\right)$ in $(X, d)$ is a triangle $\bar{\Delta}\left(x_{1}, x_{2}, x_{3}\right):=\Delta\left(\bar{x}_{1}, \bar{x}_{2}, \bar{x}_{3}\right)$ in the Euclidean space $R^{2}$ such that $d_{R^{2}}\left(\bar{x}_{i}, \bar{x}_{j}\right)=d\left(x_{i}, x_{j}\right)$ for $i, j \in\{1,2,3\}$.

A geodesic space is said to be a CAT(0) space if for each geodesic triangle $\Delta\left(x_{1}, x_{2}, x_{3}\right)$ in $X$ and its comparison triangle $\bar{\Delta}:=\Delta\left(\bar{x}_{1}, \bar{x}_{2}, \bar{x}_{3}\right)$ in $\mathcal{R}^{2}$, the CAT(0) inequality

$$
d(x, y) \leq d_{\mathbb{E}^{2}}(\bar{x}, \bar{y})
$$

is satisfied for all $x, y \in \Delta$ and $\bar{x}, \bar{y} \in \bar{\Delta}$.

In this paper, we write $(1-t) x \oplus t y$ for the unique point $z$ in the geodesic segment joining from $x$ to $y$ such that

$$
d(x, z)=t d(x, y), \quad d(y, z)=(1-t) d(x, y) .
$$

We also denote by $[x, y]$ the geodesic segment joining from $x$ to $y$, that is, $[x, y]=\{(1-t) x \oplus$ $t y: t \in[0,1]\}$.

A subset $C$ of a $C A T(0)$ space $X$ is said to be convex if $[x, y] \subset C$ for all $x, y \in C$.

Lemma 2.1 (see [14]). A geodesic space $X$ is a CAT(0) space, if and only if the following inequality

$$
d((1-t) x \oplus t y, z)^{2} \leq(1-t) d(x, z)^{2}+t d(y, z)^{2}-t(1-t) d(x, y)^{2}
$$

is satisfied for all $x, y, z \in X$ and $t \in[0,1]$. In particular, if $x, y, z$ are points in a CAT(0) space and $t \in[0,1]$, then

$$
d((1-t) x \oplus t y, z) \leq(1-t) d(x, z)+t d(y, z) .
$$


Let $\left\{x_{n}\right\}$ be a bounded sequence in a $\operatorname{CAT}(0)$ space $X$. For $x \in X$, one sets

$$
r\left(x,\left\{x_{n}\right\}\right)=\limsup _{n \rightarrow \infty} d\left(x, x_{n}\right)
$$

The asymptotic radius $r\left(\left\{x_{n}\right\}\right)$ of $\left\{x_{n}\right\}$ is given by

$$
r\left(\left\{x_{n}\right\}\right)=\inf _{x \in X}\left\{r\left(x,\left\{x_{n}\right\}\right)\right\},
$$

the asymptotic radius $r_{C}\left(\left\{x_{n}\right\}\right)$ of $\left\{x_{n}\right\}$ with respect to $C \subset X$ is given by

$$
r_{C}\left(\left\{x_{n}\right\}\right)=\inf _{x \in C}\left\{r\left(x,\left\{x_{n}\right\}\right)\right\},
$$

the asymptotic center $A\left(\left\{x_{n}\right\}\right)$ of $\left\{x_{n}\right\}$ is the set

$$
A\left(\left\{x_{n}\right\}\right)=\left\{x \in X: r\left(x,\left\{x_{n}\right\}\right)=r\left(\left\{x_{n}\right\}\right)\right\},
$$

the asymptotic center $A_{C}\left(\left\{x_{n}\right\}\right)$ of $\left\{x_{n}\right\}$ with respect to $C \subset X$ is the set

$$
A_{C}\left(\left\{x_{n}\right\}\right)=\left\{x \in C: r\left(x,\left\{x_{n}\right\}\right)=r_{C}\left(\left\{x_{n}\right\}\right)\right\} .
$$

Recall that a bounded sequence $\left\{x_{n}\right\}$ in $X$ is said to be regular if $r\left(\left\{x_{n}\right\}\right)=r\left(\left\{u_{n}\right\}\right)$ for every subsequence $\left\{u_{n}\right\}$ of $\left\{x_{n}\right\}$.

Proposition 2.2 (see [15]). If $\left\{x_{n}\right\}$ is a bounded sequence in a complete CAT(0) space X and $C$ is a closed convex subset of $X$, then

(1) there exists a unique point $u \in C$ such that

$$
r\left(u,\left\{x_{n}\right\}\right)=\inf _{x \in C} r\left(x,\left\{x_{n}\right\}\right)
$$

(2) $A\left(\left\{x_{n}\right\}\right)$ and $A_{C}\left(\left\{x_{n}\right\}\right)$ are both singleton.

Lemma 2.3 (see [16]). If $C$ is a closed convex subset of a complete $C A T(0)$ space $X$ and if $\left\{x_{n}\right\}$ is a bounded sequence in $C$, then the asymptotic center of $\left\{x_{n}\right\}$ is in $C$.

Definition 2.4 (see [17]). A sequence $\left\{x_{n}\right\}$ in a CAT(0) space $X$ is said to $\Delta$-converge to $x \in X$ if $x$ is the unique asymptotic center of $\left\{u_{n}\right\}$ for every subsequence $\left\{u_{n}\right\}$ of $\left\{x_{n}\right\}$. In this case one writes $\Delta-\lim _{n \rightarrow \infty} x_{n}=x$ and call $x$ the $\Delta$-limit of $\left\{x_{n}\right\}$.

Lemma 2.5 (see [17]). Every bounded sequence in a complete CAT(0) space always has a $\Delta$ convergent subsequence. 
Let $\left\{x_{n}\right\}$ be a bounded sequence in a CAT(0) space $X$ and let $C$ be a closed convex subset of $X$ which contains $\left\{x_{n}\right\}$. We denote the notation

$$
\left\{x_{n}\right\} \rightarrow w \quad \text { iff } \Phi(w)=\inf _{x \in C} \Phi(x)
$$

where $\Phi(x):=\limsup _{n \rightarrow \infty} d\left(x_{n}, x\right)$.

Now one gives a connection between the " $\rightarrow$ " convergence and $\Delta$-convergence.

Proposition 2.6 (see [13]). Let $\left\{x_{n}\right\}$ be a bounded sequence in a CAT(0) space $X$ and let $C$ be a closed convex subset of $X$ which contains $\left\{x_{n}\right\}$. Then

(1) $\Delta-\lim _{n \rightarrow \infty} x_{n}=x$ implies that $\left\{x_{n}\right\} \rightarrow x$;

(2) $\left\{x_{n}\right\} \rightarrow x$ and $\left\{x_{n}\right\}$ is regular imply that $\Delta-\lim _{n \rightarrow \infty} x_{n}=x$;

Let $C$ be a closed subset of a metric space $(X, d)$. Recall that a mapping $T: C \rightarrow C$ is said to be nonexpansive if

$$
d(T x, T y) \leq d(x, y), \quad \forall x, y \in X
$$

$T$ is said to be asymptotically nonexpansive if there is a sequence $\left\{k_{n}\right\} \subset[1,+\infty)$ with $\lim _{n \rightarrow \infty} k_{n}=1$ such that

$$
d\left(T^{n} x, T^{n} y\right) \leq k_{n} d(x, y), \quad \forall n \geq 1, x, y \in X
$$

$T$ is said to be closed if, for any sequence $\left\{x_{n}\right\} \subset C$ with $d\left(x_{n}, x\right) \rightarrow 0$ and $d\left(T x_{n}, y\right) \rightarrow$ 0 , then $T x=y$.

$T$ is called L-uniformly Lipschitzian, if there exists a constant $L>0$ such that

$$
d\left(T^{n} x, T^{n} y\right) \leq L d(x, y), \quad \forall x, y \in C, n \geq 1
$$

Definition 2.7. Let $(X, d)$ be a metric space and let $C$ be a closed subset of $X$. A mapping $T: C \rightarrow C$ is said to be $\left(\left\{v_{n}\right\},\left\{\mu_{n}\right\}, \zeta\right)$-total asymptotically nonexpansive if there exist nonnegative real sequences $\left\{v_{n}\right\},\left\{\mu_{n}\right\}$ with $v_{n} \rightarrow 0, \mu_{n} \rightarrow 0(n \rightarrow \infty)$ and a strictly increasing continuous function $\zeta:[0,+\infty) \rightarrow[0,+\infty)$ with $\zeta(0)=0$ such that

$$
d\left(T^{n} x, T^{n} y\right) \leq d(x, y)+v_{n} \zeta(d(x, y))+\mu_{n}, \quad \forall n \geq 1, x, y \in C
$$

Remark 2.8. (1) It is obvious that If $T$ is uniformly Lipschitzian, then $T$ is closed.

(2) From the definitions, it is to know that, each nonexpansive mapping is a asymptotically nonexpansive mapping with sequence $\left\{k_{n}=1\right\}$, and each asymptotically nonexpansive mapping is a total asymptotically nonexpansive mapping with $v_{n}=k_{n}-1$, $\mu_{n}=0$, for all $n \geq 1$, and $\zeta(t)=t, t \geq 0$. 
Lemma 2.9 (demiclosed principle for total asymptotically nonexpansive mappings). Let $C$ be a closed and convex subset of a complete CAT(0) space $X$ and let $T: C \rightarrow C$ be a L-uniformly Lipschitzian and $\left(\left\{v_{n}\right\},\left\{\mu_{n}\right\}, \zeta\right)$-total asymptotically nonexpansive mapping. Let $\left\{x_{n}\right\}$ be a bounded sequence in $C$ such that $\lim _{n \rightarrow \infty} d\left(x_{n}, T x_{n}\right)=0$ and $x_{n}-w$. Then $T w=w$.

Proof. By the definition, $x_{n}-w$ if and only if $A_{C}\left(\left\{x_{n}\right\}\right)=\{w\}$. By Lemma 2.3, we have $A\left(\left\{x_{n}\right\}\right)=\{w\}$.

Since $\lim _{n \rightarrow \infty} d\left(x_{n}, T x_{n}\right)=0$, by induction we can prove that

$$
\lim _{n \rightarrow \infty} d\left(x_{n}, T^{m} x_{n}\right)=0, \quad \forall m \geq 1
$$

In fact, it is obvious that, the conclusion is true for $m=1$. Suppose the conclusion holds for $m \geq 1$, now we prove that the conclusion is also true for $m+1$. In fact, since $T$ is a L-uniformly Lipschitzian mapping, we have

$$
\begin{aligned}
d\left(x_{n}, T^{m+1} x_{n}\right) & \leq d\left(x_{n}, T x_{n}\right)+d\left(T x_{n}, T T^{m} x_{n}\right) \\
& \leq d\left(x_{n}, T x_{n}\right)+L d\left(x_{n}, T^{m} x_{n}\right) \longrightarrow 0 \quad(\text { as } n \longrightarrow \infty) .
\end{aligned}
$$

Equation (2.16) is proved. Hence for each $x \in C$ and $m \geq 1$ from (2.16) we have

$$
\Phi(x):=\limsup _{n \rightarrow \infty} d\left(x_{n}, x\right)=\limsup _{n \rightarrow \infty} d\left(T^{m} x_{n}, x\right) .
$$

In (2.18) taking $x=T^{m} w, m \geq 1$, we have

$$
\begin{aligned}
\Phi\left(T^{m} w\right) & =\limsup _{n \rightarrow \infty} d\left(T^{m} x_{n}, T^{m} w\right) \\
& \leq \limsup _{n \rightarrow \infty}\left(d\left(x_{n}, w\right)+v_{m} \zeta\left(d\left(x_{n}, w\right)\right)+\mu_{m}\right) .
\end{aligned}
$$

Let $m \rightarrow \infty$ and taking superior limit on the both sides, it gets that

$$
\limsup _{m \rightarrow \infty} \Phi\left(T^{m} w\right) \leq \Phi(w)
$$

Furthermore, for any $n, m \geq 1$ it follows from inequality (2.3) with $t=1 / 2$ that

$$
d^{2}\left(x_{n}, \frac{w \oplus T^{m} w}{2}\right) \leq \frac{1}{2} d^{2}\left(x_{n}, w\right)+\frac{1}{2} d^{2}\left(x_{n}, T^{m} w\right)-\frac{1}{4} d^{2}\left(w, T^{m} w\right) .
$$


Let $n \rightarrow \infty$ and taking superior limit on the both sides of the above inequality, for any $m \geq 1$ we get

$$
\Phi\left(\frac{w \oplus T^{m} w}{2}\right)^{2} \leq \frac{1}{2} \Phi(w)^{2}+\frac{1}{2} \Phi\left(T^{m} w\right)^{2}-\frac{1}{4} d\left(w, T^{m} w\right)^{2}
$$

Since $A\left(\left\{x_{n}\right\}\right)=\{w\}$, we have

$$
\Phi(w)^{2} \leq \Phi\left(\frac{w \oplus T^{m} w}{2}\right)^{2} \leq \frac{1}{2} \Phi(w)^{2}+\frac{1}{2} \Phi\left(T^{m} w\right)^{2}-\frac{1}{4} d\left(w, T^{m} w\right)^{2}, \quad \forall m \geq 1
$$

which implies that

$$
d^{2}\left(w, T^{m} w\right) \leq 2 \Phi\left(T^{m} w\right)^{2}-2 \Phi(w)^{2}
$$

By (2.20) and (2.24), we have $\lim _{m \rightarrow \infty} d\left(w, T^{m} w\right)=0$. This implies that $\lim _{m \rightarrow \infty} d(w$, $\left.T^{m+1} w\right)=0$. Since $T$ is uniformly Lipschitzian, $T$ is uniformly continuous. Hence we have $T w=w$. This completes the proof of Lemma 2.9.

The following proposition can be obtained from Lemma 2.9 immediately which is a generalization of Kirk and Panyanak [17] and Nanjaras and Panyanak [13].

Proposition 2.10. Let $C$ be a closed and convex subset of a complete CAT(0) space $X$ and let $T$ : $C \rightarrow C$ be an asymptotically nonexpansive mapping. Let $\left\{x_{n}\right\}$ be a bounded sequence in $C$ such that $\lim _{n \rightarrow \infty} d\left(x_{n}, T x_{n}\right)=0$ and $\Delta-\lim _{n \rightarrow \infty} x_{n}=w$. Then $T(w)=w$.

Definition 2.11 (see [18]). Let $X$ be a CAT(0) space then $X$ is uniformly convex, that is, for any given $r>0, \epsilon \in(0,2]$ and $\lambda \in[0,1]$, there exists a $\eta(r, \epsilon)=\epsilon^{2} / 8$ such that, for all $x, y, z \in X$,

$$
\left.\begin{array}{r}
d(x, z) \leq r \\
d(y, z) \leq r \\
d(x, y) \geq \epsilon r
\end{array}\right\} \Longrightarrow d((1-\lambda) x \oplus \lambda y, z) \leq\left(1-2 \lambda(1-\lambda) \frac{\epsilon^{2}}{8}\right) r
$$

where the function $\eta:(0, \infty) \times(0,2] \rightarrow(0,1]$ is called the modulus of uniform convexity of $\operatorname{CAT}(0)$.

Lemma 2.12 (see [14]). If $\left\{x_{n}\right\}$ is a bounded sequence in a complete CAT $(0)$ space with $A\left(\left\{x_{n}\right\}\right)=$ $\{x\},\left\{u_{n}\right\}$ is a subsequence of $\left\{x_{n}\right\}$ with $A\left(\left\{u_{n}\right\}\right)=\{u\}$, and the sequence $\left\{d\left(x_{n}, u\right)\right\}$ converges, then $x=u$.

Lemma 2.13. Let $\left\{a_{n}\right\},\left\{b_{n}\right\}$, and $\left\{\delta_{n}\right\}$ be sequences of nonnegative real numbers satisfying the inequality

$$
a_{n+1} \leq\left(1+\delta_{n}\right) a_{n}+b_{n}
$$

If $\Sigma_{n=1}^{\infty} \delta_{n}<\infty$ and $\sum_{n=1}^{\infty} b_{n}<\infty$, then $\left\{a_{n}\right\}$ is bounded and $\lim _{n \rightarrow \infty} a_{n}$ exists. 
Lemma 2.14 (see [13]). Let $X$ be a $C A T(0)$ space, $x \in X$ be a given point and $\left\{t_{n}\right\}$ be a sequence in $[b, c]$ with $b, c \in(0,1)$ and $0<b(1-c) \leq 1 / 2$. Let $\left\{x_{n}\right\}$ and $\left\{y_{n}\right\}$ be any sequences in $X$ such that

$$
\begin{gathered}
\limsup _{n \rightarrow \infty} d\left(x_{n}, x\right) \leq r, \quad \limsup _{n \rightarrow \infty} d\left(y_{n}, x\right) \leq r, \\
\lim _{n \rightarrow \infty} d\left(\left(1-t_{n}\right) x_{n} \oplus t_{n} y_{n}, x\right)=r
\end{gathered}
$$

for some $r \geq 0$. Then

$$
\lim _{n \rightarrow \infty} d\left(x_{n}, y_{n}\right)=0
$$

\section{Main Results}

In this section, we will prove our main theorem.

Theorem 3.1. Let $C$ be a nonempty bounded closed and convex subset of a complete $C A T(0)$ space X. Let $S: C \rightarrow C$ be a asymptotically nonexpansive mapping with sequence $\left\{k_{n}\right\} \subset[1, \infty), k_{n} \rightarrow 1$ and $T: C \rightarrow C$ be a uniformly L-Lipschitzian and $\left(\left\{v_{n}\right\},\left\{\mu_{n}\right\}, \zeta\right)$-total asymptotically nonexpansive mapping such that $\mathcal{F}=F(S) \cap F(T) \neq \emptyset$. From arbitrary $x_{1} \in C$, defined the sequence $\left\{x_{n}\right\}$ as follows:

$$
\begin{gathered}
y_{n}=\alpha_{n} S^{n} x_{n} \oplus\left(1-\alpha_{n}\right) x_{n}, \\
x_{n+1}=\beta_{n} T^{n} y_{n} \oplus\left(1-\beta_{n}\right) x_{n}
\end{gathered}
$$

for all $n \geq 1$, where $\left\{\beta_{n}\right\}$ is a sequence in $(0,1)$. If the following conditions are satisfied:

(i) $\sum_{n=1}^{\infty} v_{n}<\infty ; \sum_{n=1}^{\infty} \mu_{n}<\infty ; \sum_{n=1}^{\infty}\left(k_{n}-1\right)<\infty$;

(ii) there exists a constant $M^{*}>0$ such that $\zeta(r) \leq M^{*} r, r \geq 0$;

(iii) there exist constants $b, c \in(0,1)$ with $0<b(1-c) \leq 1 / 2$ such that $\left\{\alpha_{n}\right\} \subset[b, c]$;

(iv) $\sum_{n=1}^{\infty} \sup \left\{d\left(z, S^{n} z\right): z \in B\right\}<\infty$ for each bounded subset $B$ of $C$.

Then the sequence $\left\{x_{n}\right\} \Delta$-converges to a fixed point of $\mathcal{F}$.

Proof. We divide the proof of Theorem 3.1 into four steps.

(I) First we prove that for each $p \in \mathcal{F}$ the following limit exists

$$
\lim _{n \rightarrow \infty} d\left(x_{n}, p\right)
$$


In fact, for each $p \in \mathcal{F}$, we have

$$
\begin{aligned}
d\left(y_{n}, p\right) & =d\left(\alpha_{n} S^{n} x_{n} \oplus\left(1-\alpha_{n}\right) x_{n}, p\right) \\
& \leq \alpha_{n} d\left(S^{n} x_{n}, p\right)+\left(1-\alpha_{n}\right) d\left(x_{n}, p\right) \\
& =\alpha_{n} d\left(S^{n} x_{n}, S^{n} p\right)+\left(1-\alpha_{n}\right) d\left(x_{n}, p\right) \\
& \leq \alpha_{n} k_{n} d\left(x_{n}, p\right)+\left(1-\alpha_{n}\right) d\left(x_{n}, p\right) \\
& =\left(1+\alpha_{n}\left(k_{n}-1\right)\right) d\left(x_{n}, p\right) \\
d\left(x_{n+1}, p\right) & =d\left(\beta_{n} T^{n} y_{n} \oplus\left(1-\beta_{n}\right) x_{n}, p\right) \\
& \leq \beta_{n} d\left(T^{n} y_{n}, p\right)+\left(1-\beta_{n}\right) d\left(x_{n}, p\right) \\
& =\beta_{n} d\left(T^{n} y_{n}, T^{n} p\right)+\left(1-\beta_{n}\right) d\left(x_{n}, p\right) \\
& \leq \beta_{n}\left(d\left(y_{n}, p\right)+v_{n} \zeta\left(d\left(y_{n}, p\right)\right)+\mu_{n}\right)+\left(1-\beta_{n}\right) d\left(x_{n}, p\right) \\
& \leq \beta_{n}\left(d\left(y_{n}, p\right)+v_{n} M^{*} d\left(y_{n}, p\right)+\mu_{n}\right)+\left(1-\beta_{n}\right) d\left(x_{n}, p\right) \\
& \leq d\left(x_{n}, p\right)+\beta_{n} \alpha_{n}\left(k_{n}-1\right) d\left(x_{n}, p\right)+\beta_{n} v_{n} M^{*}\left(1+\alpha_{n}\left(k_{n}-1\right)\right) d\left(x_{n}, p\right)+\mu_{n} \\
& \leq\left[1+\left(k_{n}-1\right)+v_{n} M^{*}\left(1+\alpha_{n}\left(k_{n}-1\right)\right)\right] d\left(x_{n}, p\right)+\mu_{n} .
\end{aligned}
$$

It follows from Lemma 2.13 that $\left\{d\left(x_{n}, p\right)\right\}$ is bounded and $\lim _{n \rightarrow \infty} d\left(x_{n}, p\right)$ exists. Without loss of generality, we can assume $\lim _{n \rightarrow \infty} d\left(x_{n}, p\right)=c \geq 0$.

(II) Next we prove that

$$
\lim _{n \rightarrow \infty} d\left(x_{n}, T x_{n}\right)=0
$$

In fact, since

$$
\begin{aligned}
d\left(T^{n} y_{n}, p\right) & =d\left(T^{n} y_{n}, T^{n} p\right) \\
& \leq d\left(y_{n}, p\right)+v_{n} \zeta\left(d\left(y_{n}, p\right)\right)+\mu_{n} \\
& \leq\left(1+v_{n} M^{*}\right) d\left(y_{n}, p\right)+\mu_{n} \\
& \leq\left(1+v_{n} M^{*}\right)\left(1+\alpha_{n}\left(k_{n}-1\right)\right) d\left(x_{n}, p\right)+\mu_{n}
\end{aligned}
$$

for all $n \in \mathbb{N}$ and $p \in \mathcal{F}$, we have

$$
\limsup _{n \rightarrow \infty} d\left(T^{n} y_{n}, p\right) \leq c
$$

On the other hand, since

$$
\lim _{n \rightarrow \infty} d\left(\beta_{n} T^{n} y_{n} \oplus\left(1-\beta_{n}\right) x_{n}, p\right)=\lim _{n \rightarrow \infty} d\left(x_{n+1}, p\right)=c,
$$


Abstract and Applied Analysis

by Lemma 2.14 , we have

$$
\lim _{n \rightarrow \infty} d\left(T^{n} y_{n}, x_{n}\right)=0 .
$$

From condition (iv), we have

$$
\begin{aligned}
d\left(x_{n}, y_{n}\right) & =d\left(x_{n},\left(1-\alpha_{n}\right) x_{n} \oplus \alpha_{n} S^{n} x_{n}\right) \\
& \leq \alpha_{n} d\left(x_{n}, S^{n} x_{n}\right) \longrightarrow 0 \quad(n \longrightarrow \infty) .
\end{aligned}
$$

Hence from (3.8) and (3.9) we have that

$$
\begin{aligned}
d\left(x_{n}, T^{n} x_{n}\right) & \leq d\left(x_{n}, T^{n} y_{n}\right)+d\left(T^{n} y_{n}, T^{n} x_{n}\right) \\
& \leq d\left(x_{n}, T^{n} y_{n}\right)+L d\left(y_{n}, x_{n}\right) \longrightarrow 0 \quad(n \longrightarrow \infty)
\end{aligned}
$$

By (3.9) and (3.10) it gets that

$$
\begin{aligned}
d\left(x_{n+1}, T^{n} x_{n}\right) & =d\left(\left(1-\beta_{n}\right) x_{n} \oplus \beta_{n} T^{n} y_{n}, T^{n} x_{n}\right) \\
& \leq\left(1-\beta_{n}\right) d\left(x_{n}, T^{n} x_{n}\right)+\beta_{n} d\left(T^{n} y_{n}, T^{n} x_{n}\right) \\
& \leq\left(1-\beta_{n}\right) d\left(x_{n}, T^{n} x_{n}\right)+\beta_{n} L d\left(y_{n}, x_{n}\right) \longrightarrow 0 \quad(n \longrightarrow \infty) .
\end{aligned}
$$

Hence from (3.10) and (3.11) we have that

$$
d\left(x_{n}, x_{n+1}\right) \longrightarrow 0 \quad(n \longrightarrow \infty) .
$$

Again since $T$ is uniformly $L$-Lipschitzian, from (3.10) and (3.12) we have that

$$
\begin{aligned}
d\left(x_{n}, T x_{n}\right) & \leq d\left(x_{n}, x_{n+1}\right)+d\left(x_{n+1}, T^{n+1} x_{n+1}\right)+d\left(T^{n+1} x_{n+1}, T^{n+1} x_{n}\right)+d\left(T^{n+1} x_{n}, T x_{n}\right) \\
& \leq(L+1) d\left(x_{n}, x_{n+1}\right)+d\left(x_{n+1}, T^{n+1} x_{n+1}\right)+L d\left(T^{n} x_{n}, x_{n}\right) \longrightarrow 0 \quad(n \longrightarrow \infty) .
\end{aligned}
$$

Equation (3.4) is proved.

(III) Now we prove that

$$
w_{\omega}\left(x_{n}\right):=\bigcup_{\left\{u_{n}\right\} \subset\left\{x_{n}\right\}} A\left(\left\{u_{n}\right\}\right) \subset \mathcal{F}
$$

and $w_{\omega}\left(x_{n}\right)$ consists exactly of one point. 
In fact, let $u \in w_{\omega}\left(x_{n}\right)$, then there exists a subsequence $\left\{u_{n}\right\}$ of $\left\{x_{n}\right\}$ such that $A\left(\left\{u_{n}\right\}\right)=$ $\{u\}$. By Lemmas 2.5 and 2.3, there exists a subsequence $\left\{v_{n}\right\}$ of $\left\{u_{n}\right\}$ such that $\Delta-\lim _{n \rightarrow \infty} v_{n}=$ $v \in C$. By Lemma 2.9, we have $v \in F(T) \subset \mathcal{F}$. By Lemma 2.12, $u=v$. This shows that $w_{\omega}\left(x_{n}\right) \subset \mathcal{F}$.

Let $\left\{u_{n}\right\}$ be a subsequence of $\left\{x_{n}\right\}$ with $A\left(\left\{u_{n}\right\}\right)=\{u\}$ and let $A\left(\left\{x_{n}\right\}\right)=\{x\}$. Since $u \in w_{\omega}\left(x_{n}\right) \subset \mathcal{F}$ and $\left\{d\left(x_{n}, u\right)\right\}$ converges, by Lemma 2.12, we have $x=u$. This shows that $w_{\omega}\left(x_{n}\right)$ consists of exactly one point.

(IV) Finally we prove $\left\{x_{n}\right\} \Delta$-converges to a point of $\mathcal{F}$.

In fact, it follows from (3.2) that $\left\{d\left(x_{n}, p\right)\right\}$ is convergent for each $p \in \mathbb{F}$. By (3.4) $\lim _{n \rightarrow \infty} d\left(x_{n}, T x_{n}\right)=0$. By $(3.14) w_{\omega}\left(x_{n}\right) \subset \mathcal{F}$ and $w_{\omega}\left(x_{n}\right)$ consists of exactly one point. This shows that $\left\{x_{n}\right\} \Delta$-converges to a point of $\mathcal{F}$.

This completes the proof of Theorem 3.1.

\section{Conflict of Interests}

The authors declare that they have no competing interests.

\section{Authors' Contribution}

All the authors contributed equally to the writing of the present article. And they also read and approved the final paper.

\section{Acknowledgments}

The authors would like to express their thanks to the referees for their helpful suggestions and comments. This study was supported by the Scientific Research Fund of Sichuan Provincial Education Department (12ZB346).

\section{References}

[1] W. A. Kirk, "Geodesic geometry and fixed point theory," in Seminar of Mathematical Analysis: Proceedings, Universities of Malaga and Seville (Spain), September 2002-February 2003, vol. 64 of Colección Abierta, pp. 195-225, Seville University Publications, Seville, Spain, 2003.

[2] W. A. Kirk, "Geodesic geometry and fixed point theory II," in International Conference on Fixed Point Theory and Applications, pp. 113-142, Yokohama Publications, Yokohama, Japan, 2004.

[3] S. Dhompongsa, W. Fupinwong, and A. Kaewkhao, "Common fixed points of a nonexpansive semigroup and a convergence theorem for Mann iterations in geodesic metric spaces," Nonlinear Analysis, vol. 70, no. 12, pp. 4268-4273, 2009.

[4] S. Dhompongsa, W. A. Kirk, and B. Sims, "Fixed points of uniformly Lipschitzian mappings," Nonlinear Analysis, vol. 65, no. 4, pp. 762-772, 2006.

[5] N. Hussain and M. A. Khamsi, "On asymptotic pointwise contractions in metric spaces," Nonlinear Analysis, vol. 71, no. 10, pp. 4423-4429, 2009.

[6] A. Kaewcharoen and W. A. Kirk, "Proximinality in geodesic spaces," Abstract and Applied Analysis, vol. 2006, Article ID 43591, 10 pages, 2006.

[7] N. Shahzad and J. Markin, "Invariant approximations for commuting mappings in CAT(0) and hyperconvex spaces," Journal of Mathematical Analysis and Applications, vol. 337, no. 2, pp. 1457-1464, 2008. 
[8] L. Leustean, "A quadratic rate of asymptotic regularity for CAT(0)-spaces," Journal of Mathematical Analysis and Applications, vol. 325, no. 1, pp. 386-399, 2007.

[9] N. Shahzad, "Fixed point results for multimaps in CAT(0) spaces," Topology and Its Applications, vol. 156, no. 5, pp. 997-1001, 2009.

[10] N. Shahzad, "Invariant approximations in CAT(0) spaces," Nonlinear Analysis, vol. 70, no. 12, pp. 4338-4340, 2009.

[11] F. E. Browder, "Semicontractive and semiaccretive nonlinear mappings in Banach spaces," Bulletin of the American Mathematical Society, vol. 74, pp. 660-665, 1968.

[12] H. K. Xu, "Existence and convergence for fixed points of mappings of asymptotically nonexpansive type," Nonlinear Analysis, vol. 16, no. 12, pp. 1139-1146, 1991.

[13] B. Nanjaras and B. Panyanak, "Demiclosed principle for asymptotically nonexpansive mappings in CAT(0) spaces," Fixed Point Theory and Applications, vol. 2010, Article ID 268780, 14 pages, 2010.

[14] S. Dhompongsa and B. Panyanak, "On $\Delta$-convergence theorems in CAT(0) spaces," Computers $\mathcal{E}$ Mathematics with Applications, vol. 56, no. 10, pp. 2572-2579, 2008.

[15] S. Dhompongsa, W. A. Kirk, and B. Sims, "Fixed points of uniformly Lipschitzian mappings," Nonlinear Analysis, vol. 65, no. 4, pp. 762-772, 2006.

[16] S. Dhompongsa, W. A. Kirk, and B. Panyanak, "Nonexpansive set-valued mappings in metric and Banach spaces," Journal of Nonlinear and Convex Analysis, vol. 8, no. 1, pp. 35-45, 2007.

[17] W. A. Kirk and B. Panyanak, "A concept of convergence in geodesic spaces," Nonlinear Analysis, vol. 68, no. 12, pp. 3689-3696, 2008.

[18] L. Leustean, "A quadratic rate of asymptotic regularity for CAT(0)-spaces," Journal of Mathematical Analysis and Applications, vol. 325, no. 1, pp. 386-399, 2007. 


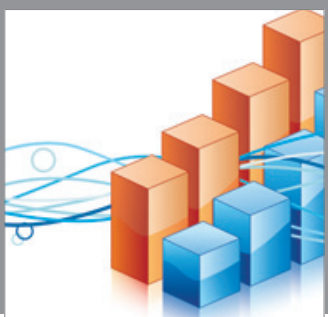

Advances in

Operations Research

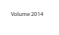

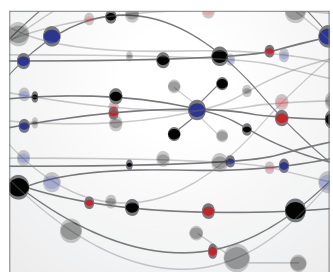

\section{The Scientific} World Journal
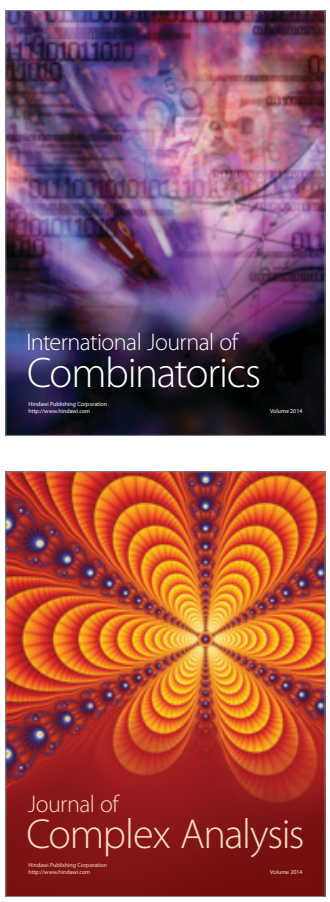

International Journal of

Mathematics and

Mathematical

Sciences
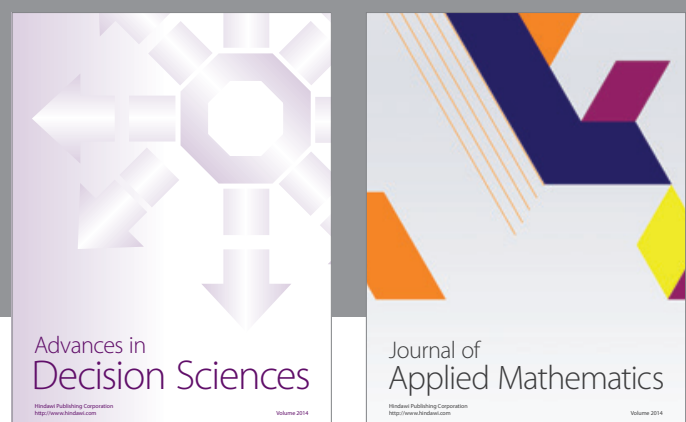

Journal of

Applied Mathematics
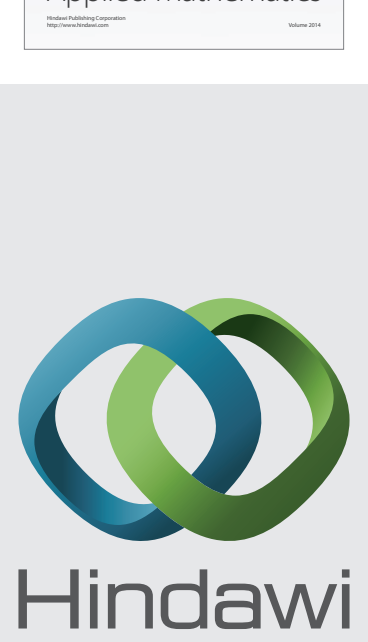

Submit your manuscripts at http://www.hindawi.com
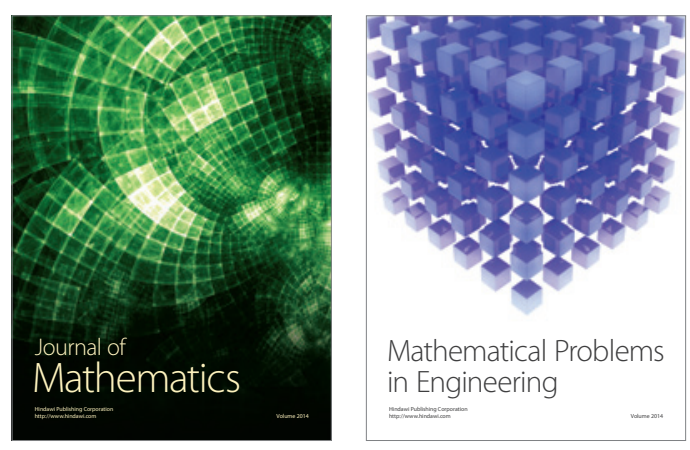

Mathematical Problems in Engineering
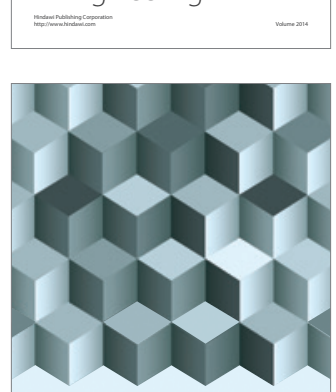

Journal of

Function Spaces
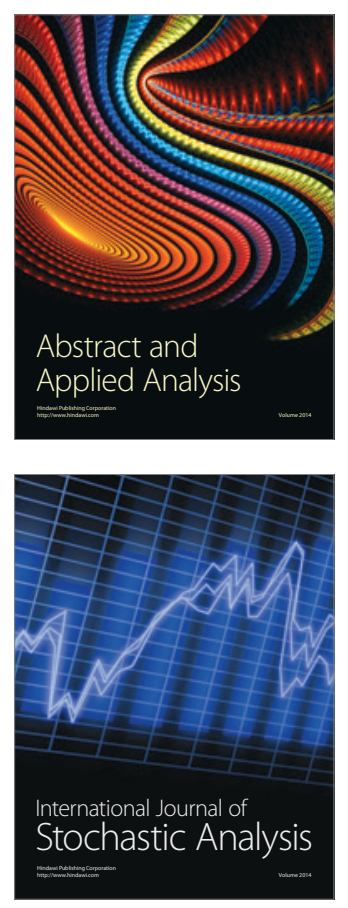

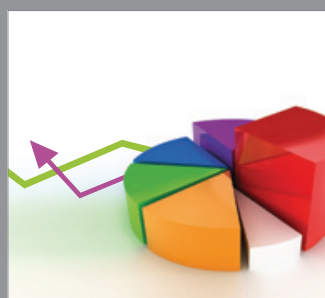

ournal of

Probability and Statistics

Promensencen
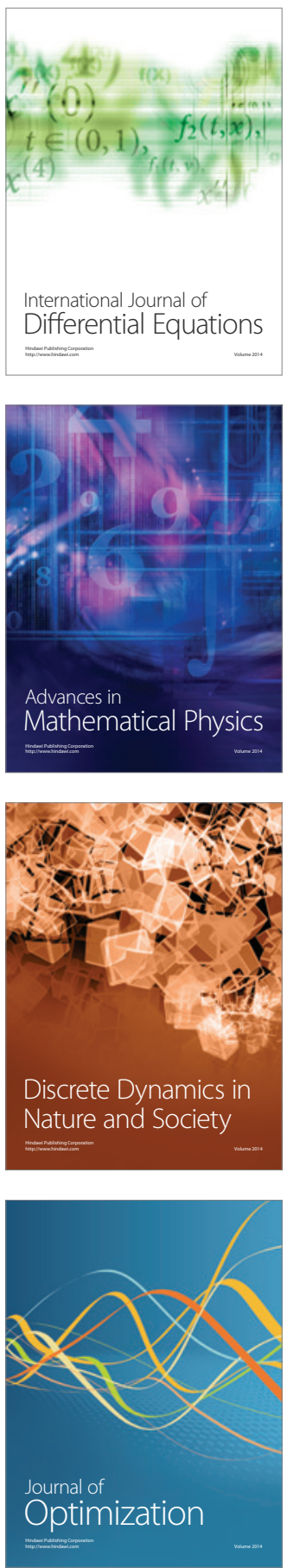